\title{
Methodology of grain heap quantity and structure determination and economic evaluation of harvester-thresher cleaning enhancement
}

\author{
Evgenia Muratova $^{1}$, Denis Muratov ${ }^{1, *}$, Elena Makarenko $^{2}$, Sergey Shepelev ${ }^{3}$, Olga \\ Korobeynikova $^{4}$, Valeriia Chegge ${ }^{1}$, and Yana Kabanova ${ }^{1}$ \\ ${ }^{1}$ Don State Technical University, 1, Gagarina sq, 344003, Rostov-on-Don, Russia \\ ${ }^{2}$ Rostov State University of Economics, 69, st. Bolshaya Sadovaya, 344002, Rostov-on-Don, Russia \\ ${ }^{3}$ South Ural State Agrarian University, 75, Lenin Avenue, 454080, Chelyabinsk, Russia \\ ${ }^{4}$ Volgograd State Technical University, 28, prosp. V.I. Lenin, 400005, Volgograd, Russia
}

\begin{abstract}
Analytical studies concerning the issues of heap supply for harvester-thresher cleaning, composition of tailings and the amount of grain are presented in the paper. The urgent problem of increasing the separation of air-sieve cleaning of modern combines is outlined. The schematic structure of the combine thresher is presented. The calculation of the grain mass quantity which is received for cleaning from the threshing group, the straw rack and finish threshing device is conducted. The visual image of cleaning load depending on supply is shown. According to the calculations it is possible to predict the loading of cleaning with small grain heaps depending on the total supply of grain mass to the thresher for combines of various classes. The technical solution to improve the cleaning system of a combine harvester is suggested and economically evaluated in the paper.
\end{abstract}

\section{Introduction}

Assessment of post-crisis development capabilities of Russia suggests a retrospective analysis of the enterprises' business and operations' trend data, primarily industrial ones, taking into account the fact that the Russian economy, which is accepted by the world community as a market system, continues to retain certain features of the state-planned economy [1]. On the one hand, this refers to the raw, fuel and energy export orientation, on the other hand, to the preserved scientific and technical base of the high-tech industry. Both in terms of laying the groundwork for progressive growth and saturating the consumer market industry continues to play an important role. It should be noted that the agroindustrial complex largely determines the position of Russia in the world economy and the internal socioeconomic situation [2].

The project growth of the grain crops' yield, the reduction of grain losses by harvesting in the best agrotechnical terms sets the task of further growth of harvesters-threshers'

\footnotetext{
"Corresponding author: mdk85@inbox.ru
} 
purpose characteristics $[3,4]$.

The most important factor of the combine harvester efficiency increase is maintenance of the corresponding productivity of the threshing and separating device, which consists of three groups of working tools - a threshing machine, a rough grain heap separator and a small grain heap separator $[5,6]$.

There are true reserves for productivity increase of the threshing group of working tools by further threshing device improvement, feeder house activation, optimization of parameters and operating modes of the elements and threshing device as a whole, but the small grain heap separator continues to be a weak point [7-13].

\section{Materials and methods}

Preliminary laboratory studies have revealed high rates of small grain heaps cleaning when employing new elements, which provide pre-enrichment of the grain heap before feeding it to the cleaning sieve $[9,12]$. The purpose of the tests consisted in verifying and confirming the results of previous theoretical and experimental studies, gaining the final scheme and parameters of air-sieve cleaning with the use of pneumatic and inertia enricher of small grain heaps for the harvester-thresher. Laboratory and field tests were conducted according to standard methods, the cleaned grain, tailings from the cleaning mechanism and straw rack were processed on laboratory equipment.Schematic structure of the harvester-thresher threshing and separating device is shown in the figure 1.

As a result of research and testing, a methodology was developed to determine the composition and quantity of grain heap feeding to the cleaning of a harvester-thresher. Let us introduce the following identifying symbols:

$\mathrm{Q}$ - grain mass supply (feed stock).

$\mathrm{Q}_{\mathrm{MZV}}$ - quantity of supplied small grain heap;

$\mathrm{Q}_{\mathrm{SOL}}$ - quantity of supplied straw;

Q

$\mathrm{q}_{\mathrm{MZV}}$ - quantity of segregated small grain heap;

$\mathrm{q}_{\mathrm{SoL}}$ - quantity of segregated straw;

qoBSH - quantity of segregated combined mass grain + straw.

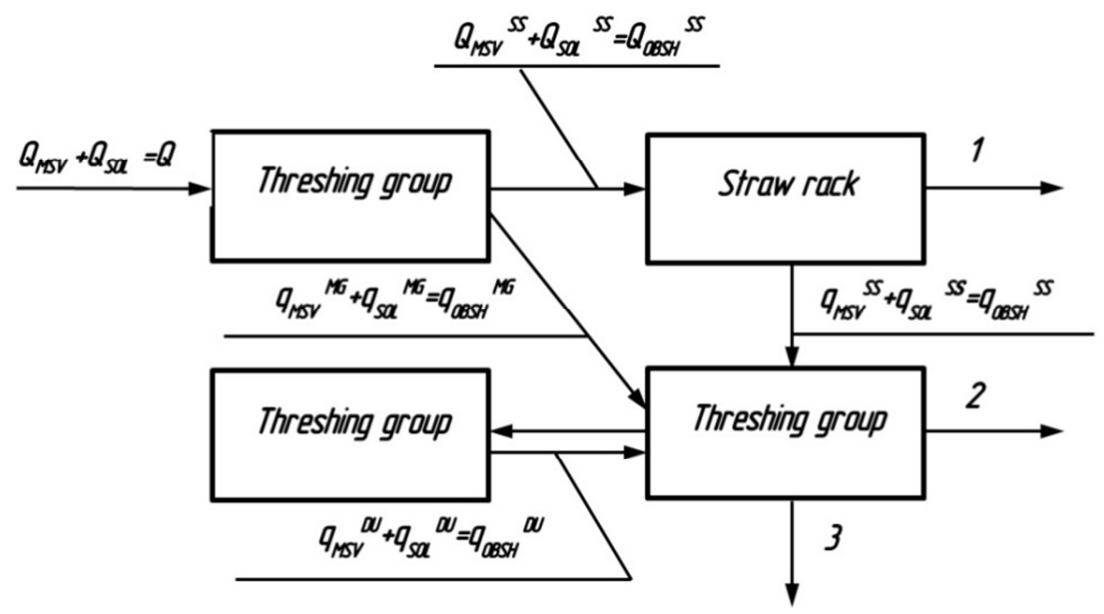

Fig. 1. Schematic structure of the harvester-thresher threshing and separating device: Q - supply and handling abilities of grain material (content of $\mathrm{j}$-components $\mathrm{Bj}$ in the grain material, humidity $\mathrm{W}$ and density $\rho$ of the grain material); 1 - portion of generated straw; 2 - portion of large and light waste; 3 cleaned grain. 


\subsection{Calculation of the quantity of grain mass received from the threshing group for air-sieve cleaning}

Let us assume that the ratio of grain to straw is $1 / 1.5$ [12].

The quantity of small grain heap received in the threshing group $Q_{M Z V}$ :

$$
Q_{M Z V}=\frac{Z}{Z+S} \cdot Q=\frac{1}{1+1,5} \cdot Q=0,4 \cdot Q
$$

where $\mathrm{Z}$ is grain; $\mathrm{S}$ is straw.

The quantity of straw received in the threshing group $Q_{S O L}$ :

$$
Q_{S O L}=Q-0,4 \cdot Q=0,6 \cdot Q
$$

The quantity of small grain heap segregated during threshing under the concave $q_{M Z V}^{M G}$ is equal to approximately $85-90 \%$ of the total feed [9]:

$$
q_{M Z V}^{M G}=0,9 \cdot(0,4 \cdot Q)=0,36 \cdot Q
$$

The quantity of straw segregated during threshing under the concave $q_{S O L}^{M G}$ :

$$
\frac{q_{S O L}^{M G}}{q_{S O L}^{M G}+q_{M Z V}^{M G}}=0,35 \rightarrow q_{S O L}^{M G}=\frac{0,35}{1-0,35} \cdot q_{M Z V}^{M G}=0,194 \cdot Q,
$$

where $30-35 \%$ is the percent of tailings in the structure of small grain heap [9].

The quantity of combined mass grain + straw segregated during threshing under the concave $q_{O B S H}^{M G}$ :

$$
q_{O B S H}^{M G}=q_{M Z V}^{M G}+q_{S O L}^{M G}=0,554 \cdot Q
$$

\subsection{Calculation of grain mass supplied for cleaning from the straw rack}

The quantity of small grain heap received in the straw rack $Q_{M Z V}^{S S}$ :

$$
Q_{M Z V}^{S S}=\left(Q_{M Z V}-q_{M Z V}^{M G}\right)
$$

The quantity of straw received in the straw rack $Q_{S O L}^{S S}$ :

$$
Q_{S O L}^{S S}=\left(Q_{S O L}-q_{S O L}^{M G}\right)
$$

The quantity of combined mass received in the straw rack $Q_{O B S H}^{S S}$ :

$$
Q_{O B S H}^{S S}=Q_{M Z V}^{S S}+Q_{S O L}^{S S}=0,446 \cdot Q
$$


The quantity of small grain heap supplied for the air-sieve cleaning after separation in the straw rack $q_{M Z V}^{S S}$ :

$$
q_{M Z V}^{S S}=\left(Q_{M Z V}-q_{M Z V}^{M G}\right) \cdot\left(1-\frac{\alpha}{100}\right)=0,0396 \cdot Q,
$$

where $\alpha$ is acceptable grain loss after separation in the straw rack, $\alpha=1 \%$ [12].

The quantity of straw supplied for the air-sieve cleaning from the straw rack $q_{S O L}^{S S}$ is approximately equal to $\beta=3 \ldots .5 \%[12]$ :

$$
q_{S O L}^{S S}=\left(Q_{S O L}-q_{S O L}^{M G}\right) \cdot \frac{\beta}{100}=0,0203 \cdot Q .
$$

The quantity of combined grain mass (grain + straw) supplied for the air-sieve cleaning from the straw rack $q_{O B S H}^{S S}$ :

$$
q_{O B S H}^{S S}=q_{M Z V}^{S S}+q_{S O L}^{S S}=0,0599 \cdot Q .
$$

\subsection{Calculation of the quantity of grain mass received from the finish threshing device for air-sieve cleaning}

The quantity of small grain heap returned to the air-sieve cleaning after finish threshing device $q_{M Z V}^{D U}$ approximately reaches 5\%[12]:

$$
q_{M Z V}^{D U}=\left(q_{M Z V}^{M G}+q_{M Z V}^{S S}\right) \cdot 0,05=0,01998 \cdot Q .
$$

The quantity of straw returned to the air-sieve cleaning after finish threshing device $q_{S O L}^{D U}$ approximately reaches $5 \%[12]$ :

$$
q_{S O L}^{D U}=\left(q_{S O L}^{M G}+q_{S O L}^{S S}\right) \cdot 0,05=0,010715 \cdot Q .
$$

The quantity of combined grain mass (grain + straw) returned for the air-sieve cleaning after finish threshing device $q_{O B S H}^{D U}$ :

$$
q_{O B S H}^{D U}=q_{M Z V}^{D U}+q_{S O L}^{D U}=0,030695 \cdot Q
$$

\subsection{Total calculation of the quantity of grain mass supplied for air-sieve cleaning}

The total quantity of small grain heap supplied for air-sieve cleaning $Q_{M Z V}^{O C H}$ :

$$
Q_{M Z V}^{O C H}=q_{M Z V}^{M G}+q_{M Z V}^{S S}+q_{M Z V}^{D U}=0,41958 \cdot Q
$$

The total quantity of straw supplied for air-sieve cleaning $Q_{S O L}^{O C H}$ : 


$$
Q_{S O L}^{O C H}=q_{S O L}^{M G}+q_{S O L}^{S S}+q_{S O L}^{D U}=0,225015 \cdot Q .
$$

The total quantity of combined grain mass (grain + straw) supplied for air-sieve cleaning $Q_{O B S H}^{O C H}$ :

$$
Q_{O B S H}^{O C H}=q_{O B S H}^{M G}+q_{O B S H}^{S S}+q_{O B S H}^{D U}=0,644595 \cdot Q .
$$

Authors suggest that the use of designed technical device, namely, the pneumatic and inertia enricher of small grain heap allows to reduce grain losses and increase efficiency of harvester-thresher's cleaning process [9].

\subsection{Calculation of economic efficiency of the harvester-thresher cleaning enhancement}

Let us calculate the economic efficiency achieved as a result of the implementation of suggested technical solution, using methodologies described in the sources [14, 15]. In the project case (assuming the use of pneumatic and inertia enricher), the decrease of grain loss is evidenced in the process of air-sieve cleaning by $0.25 \%$ compared to the base case $(0.5 \%)$. Thus, the total grain loss of combine harvester will be reduced from $1.5 \%$ to $1.25 \%$. The volume of season grain losses for combines $P_{z e r}^{b a z}$ is defined as:

$$
P_{z e r}^{b a z}=0.015 \times F_{z} \times U_{s r},
$$

where $F_{z}$ is the area of grain crops of one farm unit, ha (averagely, it is possible to set to 4200 ha in the Rostov region); [16]

$U_{s r}$ is the average yield of grain crops, ton / ha (in accordance with the data of the Federal State Statistics Service, it is equal to 3.46 ton / ha in 2019).

Loss of grain in the base case:

$$
P_{z e r}^{\text {baz }}=0.015 \times 4200 \times 3.46=217.98 \text { ton }
$$

Similarly, it is possible to calculate the grain loss in project case $P_{z e r}^{p r}$ using a formula:

$$
P_{z e r}^{p r}=0.0125 \times F_{z} \times U_{s r}
$$

Loss of grain in the project case:

$$
P_{z e r}^{p r}=0.0125 \times 4200 \times 3.46=181.65 \text { ton }
$$

Consequently, it is possible to determine the volume of additional production for the season $D_{p}$ using a formula:

$$
D_{p}=P_{z e r}^{b a z}-P_{z e r}^{p r}
$$

The volume of additional production for the season:

$$
D_{p}=217.98-181.65=36.33 \text { ton }
$$

Next, the cost of additional production $S_{\text {dop } 1}$ can be defined according to a formula:

$$
S_{d o p 1}=D_{p} \times C_{z a k},
$$


where $C_{z a k}$ is the average farm-gate price of grain, rubles / ton (in accordance with the data of the Federal State Statistics Service it is equal to 10760.25 rubles in 2019).[17]

The cost of additional production obtained by reducing grain losses:

$$
S_{\text {dop } 1}=36.33 \times 10760.25=390919.88 \text { rubles }
$$

To determine the economic effect, it is necessary to calculate the amount of investment in the project, as well as annual operating expenses. The investments $K_{p r}$ include the cost of equipping combines with a pneumatic and inertia enricher and are equal to 240000 rubles for one farm unit (six combines).

The operating expenses $I_{e}$ are determined as follows:

$$
I_{e}=S_{u s t} \times\left(k_{s S}+N_{A}\right),
$$

where $S_{u s t}$ is the cost of equipping combines with a pneumatic and inertia enricher, rubles; $k_{S S}$ is the multiplier that takes into account lifetime of the equipment (can be set to 0.2); $N_{A}$ is depreciation rate per year $(10 \%)$.[18]

The annual operating expenses:

$$
I_{e}=240000 \times(0.2+0.1)=72000 \text { rubles }
$$

The evaluation of economic efficiency is performed for five years with the application of the discounting methodology. When specifying the discount rate, the inflation rate is taken into account (3\% in 2019), as well as the uncertainty level of the forecasted crop (4\%). The discount rate $\mathrm{E}$ is therefore set at a rate of $7 \%$. The discount coefficient $K_{d}$ is calculated by the formula:

$$
K_{d}=\frac{1}{(1+E)^{t}}
$$

wheret is the number of years before the reduction.[19]

The present value of additional production $D S_{d o p}$ is defined using a formula:

$$
D S_{d o p 1}=S_{d o p 1} \times K_{d}
$$

Annual economic effect $E_{g}$ is calculated as follows:

$$
E_{g}=D S_{d o p 1}-K_{p r}-I_{e}
$$

Mid-year economic effect $E_{s g}$ is determined by the formula:

$$
E_{s g}=\frac{\sum_{i=1}^{n} E_{g}}{n}
$$

Discounted payback period $T_{\text {d.ok }}$ is defined as:

$$
T_{\text {d.ok }}=\frac{K_{p r}}{E_{s g}}
$$

\section{Results}

The dependence of the cleaning load with grain heap and straw on the feed to the thresher is shown in table 1. 
Table 1. Dependence of technological parameters of air-sieve cleaning performance on supply of grain mass to the threshing and separating device of harvester-thresher.

\begin{tabular}{|c|c|c|c|c|c|c|c|c|c|c|c|c|}
\hline Supply & $\mathrm{kg} / \mathrm{s}$ & 5 & 6 & 7 & 8 & 9 & 10 & 11 & 12 & 13 & 14 & 15 \\
\hline $\begin{array}{l}\text { The } \\
\text { quantity of } \\
\text { grain } \\
\text { supplied } \\
\text { for } \\
\text { cleaning }\end{array}$ & $\mathrm{kg} / \mathrm{s}$ & 2.10 & 2.52 & 2.94 & 3.36 & 3.78 & 4.20 & 4.62 & 5.03 & 5.45 & 5.87 & 6.29 \\
\hline $\begin{array}{l}\text { The } \\
\text { quantity of } \\
\text { straw } \\
\text { supplied } \\
\text { for } \\
\text { cleaning }\end{array}$ & $\mathrm{kg} / \mathrm{s}$ & 1.13 & 1.35 & 1.58 & 1.80 & 2.03 & 2.25 & 2.48 & 2.70 & 2.93 & 3.15 & 3.38 \\
\hline $\begin{array}{l}\text { Combined } \\
\text { mass of } \\
\text { small grain } \\
\text { heap } \\
\text { supplied } \\
\text { for } \\
\text { cleaning } \\
\text { (calculated) }\end{array}$ & $\mathrm{kg} / \mathrm{s}$ & 3.22 & 3.87 & 4.51 & 5.16 & 5.80 & 6.45 & 7.09 & 7.74 & 8.38 & 9.02 & 9.67 \\
\hline
\end{tabular}

Figure 2 illustrates the dependence of the cleaning load with grain heap and straw on the feed to the thresher.

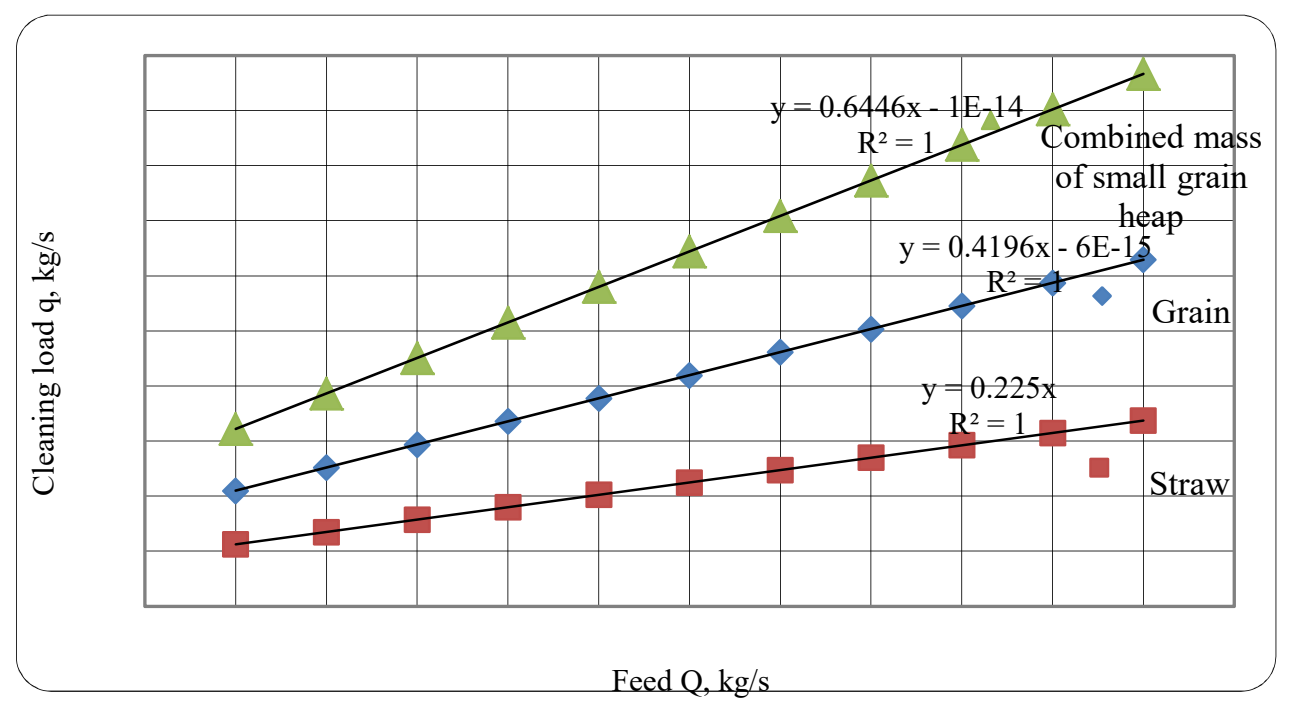

Fig. 2. The quantity of grain, straw and combined grain mass supplied for cleaning.

Table 2 summarizes the calculated indicators of economic efficiency. 
Table 2. Calculation of project discounted payback period.

\begin{tabular}{|c|c|c|c|c|c|}
\hline \multirow{2}{*}{ Indicators } & \multicolumn{5}{|c|}{ Years } \\
\hline & 1 year & 2 year & 3 year & 4 year & 5 year \\
\hline Investments, rubles & 240000 & - & - & - & - \\
\hline Operating expenses, rubles & 72000 & 72000 & 72000 & 72000 & 72000 \\
\hline $\begin{array}{l}\text { Cost of additional grain } \\
\text { production, rubles }\end{array}$ & 390919.88 & 390919.88 & 390919.88 & 390919.88 & 390919.88 \\
\hline Discount coefficient & 1 & 0.9346 & 0.8734 & 0.8163 & 0.7629 \\
\hline $\begin{array}{l}\text { Discounted cost of } \\
\text { additional grain production, } \\
\text { rubles }\end{array}$ & 390919.88 & 365345.68 & 341444.57 & 319107.07 & 298230.91 \\
\hline $\begin{array}{l}\text { Annual economic effect, } \\
\text { rubles }\end{array}$ & 78919.88 & 293345.68 & 269444.57 & 247107.07 & 226230.91 \\
\hline $\begin{array}{l}\text { Mid-year economic effect, } \\
\text { rubles }\end{array}$ & \multicolumn{5}{|c|}{223009.62} \\
\hline $\begin{array}{l}\text { Discountedpaybackperiod, } \\
\text { years }\end{array}$ & \multicolumn{5}{|c|}{1.08} \\
\hline
\end{tabular}

In addition, it is possible to determine the cost of additional products obtained by increasing the harvester-thresher productivity $S_{\text {dop.pr. }}$ using a formula:

$$
S_{\text {dop.pr. }}=\frac{U_{s r} P_{P} C_{z a k}}{100}\left[\begin{array}{c}
\frac{1+n_{2}}{2} \times n_{2} \times\left(W_{d n_{2}}-W_{d n_{1}}\right)+F_{s e z}-W_{d n_{1}} \\
\times \frac{\left(n_{2}+1\right)+n_{1}}{2} \times\left(n_{1}-n_{2}\right)
\end{array}\right],
$$

where $P_{P}$ is the percent of average grain loss, $\%$;

$W_{d n_{1}}$ and $W_{d n_{2}}$ mean the daily production of harvester-thresher in base and project cases, ha;

$n_{1}$ and $n_{2}$ mean the number of full work days per season, days;

$F_{\text {sez }}$ is the seasonal harvesting area, ha.

Indicators $W_{d n_{1}}$ and $W_{d n_{2}}$ are calculated as follows:

$$
W_{d n}=7 \times W_{c h} \times K_{s m},
$$

where $K_{s m}$ is the shift factor (set to 1.5 );

$W_{c h}$ is the production of harvester-thresher per hour of shift time, ha.

Indicators $n_{1}$ and $n_{2}$ are determined using a formula:

$$
n=\frac{F_{s e z}}{W_{d n}}
$$

Hence, the cost of additional products obtained by increasing the productivity of one harvester-thresher is equal to:

$$
\begin{aligned}
& S_{\text {dop.pr. }}=\frac{3.46 \times 0.0125 \times 10760.25}{100}\left[\begin{array}{c}
\frac{1+10.25}{2} \times 10.25 \times(68.25-59.85)+2800-59.85 \\
\times \frac{(10.25+1)+11.7}{2} \times(11.7-10.25)
\end{array}\right] \\
& =40444 \text { rubles }
\end{aligned}
$$


There are six combines operating in the concerned farm unit, consequently, the cost of additional grain production can reach 242664 rubles per season.

\section{Discussion of the results}

The above calculations make it possible to predict the cleaning load with small grain heaps depending on the total supply of grain mass to the thresher for combines of various classes. The obtained equations and dependences enable to predict the technological parameters of air-sieve cleaning performance of harvester-thresher. The analysis of harvester-thresher operation is carried out and it is established that the dependence between the grain mass supply to the thresher and the amount of small grain heap entering the air-sieve cleaning is sufficiently approximated by a linear expression in the form of a first-order polynomial describing test results. According to this equation the amount of grain supplied for cleaning, the amount of straw supplied for cleaning and the combined mass of grain + straw supplied for cleaning were calculated [20].

As far as is known, the production of grain crops in Russia is considered as one of the criteria for the country food safety state assessing. Therefore the issues concerning the increase of grain harvesting equipment productivity are particularly topical. The use of pneumatic and inertia enricher is considered as a new technical solution that can provide a grain loss reduction while increasing the performance of the harvester-thresher. In conformity with the economic calculation, the productivity growth of one combine may reach approximately 40 thousand rubles [21-22].

\section{Conclusions}

As part of the study, it was found that with the increase of grain mass supply to the combine thresher, the amount of small grain heap fed for cleaning is sufficiently approximated by a linear expression in the form of a first-order polynomial describing test results [23].

The economic calculation shows that the mid-year economic effect from the implementation of the project is 223009.62 rubles for one farm unit and the discounted payback period is 1 year. Hence, the suggested technical solutions to improve the harvesterthresher cleaning can be considered as cost-effective.

\section{References}

1. V.V. Mazur, K.A. Barmuta, S.S. Demin, E.A. Tikhomirov, M.A. Bykovskiy, Innovation clusters: Advantages and disadvantages, International Journal of Economics and Financial Issues (2016)

2. I.I. Doronina, V.N. Borobov, E.A. Ivanova, E.V. Gorynya, B.M. Zhukov, Agroindustrial clusters as a factor of increasing competitiveness of the region, International Journal of Economics and Financial Issues (2016)

3. A.E. Chernaya, M.N. Kabanenko, S.N. Ugrimova, Improvement of agro-industrial complex management at the federal level, IOP Conference Series: Earth and Environmental Science (2019)

4. A.V. Gridchina, L.L. Orekhova, S.V. Lyubimtseva, N.V. Yakovenko, I.V. Komov, Agrarian policy of the region in terms of economic development innovation, International Journal of Economics and Financial Issues (2016)

5. S. Sidorenko, E. Trubilin, E. Kolesnikova, H. Hasegawa, Mechanization in Asia, Africa and Latin America 48(2), 31-35 (2017) 
6. A.K. Subaeva, N.V. Malinina, Life Science Journal 11(9), 360-362 (2014)

7. V.P. Dimitrov, L.V., Borisova, I.N. Nurutdinova, V.I. Pakhomov, V.P. Maksimov, The problem of choice of optimal technological decisions on harvester control, MATEC Web of Conferences (2018)

8. F.A. Kipriyanov, P.A. Savinykh, Assessment of technical provision in agricultural sector of Russia, Eurasian journal of biosciences. Foundation for Enviromental Protection and Research (2019)

9. D.K. Muratov, The $6^{\text {th }}$ International science and technology conference "Innovative technologies and technical means for field cultivation in the south of Russia" (Zernograd, 2011)

10. Y. Tsarev, E. Adamcikova, M. Najie, Automatization of settings of working organs of technological process of combine harvester, MATEC Web of Conferences (2018)

11. A. Izmailov, M. Moskovskiy, D. Podlesniy, Development of a set of working units from polymeric materials for the design of combine harvesters, MATEC Web of Conferences (2018)

12. D.K. Muratov, Y.I. Ermoliev, Bulletin of Don State Technical University 8(59), 1372 $1376(2011)$

13. I. Khozyaev, V. Ladyanov, L. Enalyeva, M. Balinskaya, V. Zharov, Assessment of grain losses during harvesting of grain crops on the basis of technical and economic indicators, E3S Web of Conferences (2019)

14. Russian Federation standard GOST 34393-2018

15. B.C. Meshi, D.M. Zozulya, A.E. Safronov, Economic evaluation of the efficiency of technosphere safety improvement projects (Don State Technical University, Rostovon-Don, 2013)

16. S.I. Kambulov, I.V. Bozhko, A.V. Olshevskaya, MATEC Web of Conferences 224, 05022 (2018) https://doi.org/10.1051/matecconf/201822405022

17. Yu.A. Ivanov, V.I. Pakhomov, S.I. Kambulov, D.V. Rudoi, ICMTMTE 2018 MATEC Web of Conferences 224, 05023 https://doi.org/10.1051/matecconf/201822405023

18. A. Altybayev, A. Zhanbyrbayev, B. Meskhi, D. Rudoy, A. Olshevskaya, A. Prohorova, E3S Web of Conferences 135, 01078

(2019) https://doi.org/10.1051/e3sconf/201913501078

19. B. Meskhi, B. Golev, V. Efros, D. Rudoy, A. Olshevskaya, V. Zhurba, Y. Chayka, E3S Web of Conferences 135, 01083 (2019) https://doi.org/10.1051/e3sconf/201913501083

20. J. Gerber, A. Zavaly, A. Gavrilov, A. Olshevskaya, N. Kiyan, IOP Conf. Series: Earth and Environmental Science 403, 012014 (2019) doi:10.1088/1755-1315/403/1/012014

21. G. Parkhomenko, S. Kambulov, A. Olshevskaya, A. Babadzhanyan, N. Gucheva, I. Mekhantseva, IOP Conf. Series: Earth and Environmental Science 403, 012144 (2019) doi:10.1088/1755-1315/403/1/012144

22. Y. Lachuga, A. Soloviev, A. Matrosov, I. Panfilov, V. Pakhomov, D. Rudoy IOP Conf. Series: Earth and Environmental Science 403, 012055 (2019) doi:10.1088/1755$1315 / 403 / 1 / 012055$

23. E. Zubrilina, I. Markvo, V. Novikov, A. Beskopylny, L. Vysochkina, D. Rudoy, A. Butovchenko IOP Conf. Series: Earth and Environmental Science 403, 012063 (2019) doi:10.1088/1755-1315/403/1/012063 